\title{
Personnel Preparation Projects For Special Education: It Takes More Than Money
}

Lawrence Ingalls, University of Texas, El Paso, USA

Helen Hammond University of Texas, El Paso, USA

\begin{abstract}
The issues regarding teacher shortages and retention have been a concern for many years within the special education field. School districts have struggled at not only maintaining quality teachers to fill positions for special education programs, but also to retain these quality teachers in their districts. As an additional challenge, many communities have members that are place bound. These individuals do not wish to leave their families to move to another location to receive university training. Specific strategies used in training models from a variety of projects will be discussed.
\end{abstract}

Keywords: personnel preparation projects, special education personnel training, shortages of teachers in special education, teacher retention issues, place bound community members, paraprofessionals as educators, American Indian training programs

\section{INTRODUCTION}

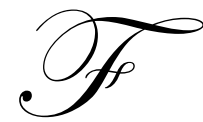

or school districts, retaining quality teachers for special education positions has been a concern for years. Compounding this challenge to fill positions, many individuals may wish to obtain post secondary training from a university; however, the individuals are place bound to their community. Some groups of individuals are culturally expected to remain close to their extended families and remain in their communities. This closeness helps to foster and reinforce the culture of the group. Although the need for post high school training to complete a Bachelor's Degree or the continuation of training with a Master's Degree is acknowledged by these individuals, the personal sacrifices they might encounter far surpass the benefits they would gain by furthering their education. However, helping these place bound individuals obtain a degree in special education and with the knowledge that they are likely to remain in their communities, would alleviate two issues that the school districts face. They would be able to secure qualified special education personnel and retain these personnel in their school district.

Professionals in the special education field have realized an effective method to address educational issues and concerns is to apply for personnel preparation funds from federal or state programs. This funding can support individuals to obtain a degree in special education. The personnel preparation project can focus on a specific set of issues, design a variety of solutions, and implement a program that addresses the needs of an unique group of potential special educators. This article will discuss a variety of personnel preparation projects across the United States that have directed their efforts at addressing: a) the shortages of well-qualified teachers in special education programs, b) teacher retention, and c) issues surrounding place bound communities and teacher training. The authors of this article have successfully been funded on numerous federally supported personnel preparation projects. Each of these funded grants was geared to decrease teacher shortages in special education and assist in retaining special education teachers in communities that have had a history of needing qualified special education personnel. Specific strategies used in the training models from each of these projects will be discussed. 


\section{PERSONNEL PREPARATION PROJECTS}

Personnel preparation projects offer school districts an opportunity to financially assist members of their community to complete Bachelors and Masters Degrees in specialized areas that the federal government has viewed as a professional shortage area in our educational settings. For years, opportunities to secure federal funding to provide personnel preparation training programs to teachers have existed. One of the greatest shortages school districts have faced is personnel specifically trained to work with children with severe disabilities. Historically, this need became evident with the movement for deinstitutionalization in the 1970s and 1980s. Later, with the move for inclusive programs in neighborhood schools, more personnel for this population of students were needed (Lang \& Fox 2003; Westling \& Fox, 2004). A recent trend supported by researchers in the field of special education is to provide very specific training for a specific disability such as autism spectrum disorders (Scheuerman, Weber, Boutot, \& Goodwin, 2003). In conjunction and collaboration with school districts, such agencies as a state department or a university can submit a proposal to a funding source requesting funds to operate this program. If funded, the project director will systematically allocate financial support to targeted individuals who meet the goals and objectives of the project.

Such researchers as Ludlow, Conner, and Schechter (2005) described their efforts to address the personnel shortages with children with severe disabilities in rural areas. They completed a national study that identified state shortages, certification patterns of the states, personnel preparation programs, and distance delivery mechanisms for training the teachers who serve students with severe disabilities. They listed a variety of strategies used in the United States to train teachers to work effectively with these students. They found some states used distance education, satellite television, interactive television, and on-line programs to reach individuals for the training. These strategies were specifically prevalent in rural areas. From the analysis of their data, they were able to outline future needed trends for personnel preparation projects in rural areas for this population of students. One critical point these authors emphasized is that as the federal mandate of the No Child Left Behind Act requires highly qualified teachers, states may find it more and more difficult to meet the demand for individuals adequately trained to serve children with low incidence disabilities. This is of particular concern for school districts located in rural communities which are far removed from urban areas with college and university programs.

Williams, Martin, and Hess (2002) completed research in personnel preparation projects that provide support to personnel who serve students with disabilities in rural areas. They found that strategies such as distance learning, on-site professional development activities, and salary incentives were commonly used. These researchers summarized that these strategies are very effective in increasing personnel shortages in special education. They also noted that institutions of higher education should consider restructuring their programs to include both general and special educators since many school districts are requiring inclusive opportunities in general education programs for students with disabilities. This common framework of training was summarized by these researchers as effective at enhancing both types of educators' experiences at the pre-service level.

Goldman (2004) discussed a variety of retention strategies used in a federally funded project, Project LEAD. This grant was a training program for minority educators in special education and educational leadership. This author emphasized the value of developing a cohort of learners among the project participants. The cohort strategy was beneficial to the participants not only as a support group during the training program but also as a support beyond the completion of coursework. The participants from this Project were noted to maintain their close professional ties after they exited the program and began their teaching careers.

Sileo and Prater (2000) stated high poverty communities with large numbers of students from diverse backgrounds encounter the greatest challenges in recruiting, supporting and training teachers. To meet the challenges, school districts have benefited from such strategies as increased salaries, cash bonuses, reimbursement for tuition expenses, and alternative certification programs for special education certification.

The authors of this article have successfully directed a variety of grants that not only have increased the number of quality teachers for the special education field, but have directed their efforts to assist personnel to complete their post secondary training in communities that are place bound. As noted earlier, these individuals are 
reluctant to leave their communities for training due to strong family obligations that are considered both immediate and extended. Therefore, creative strategies are needed to bring the training to them.

Preparing Personnel for Special Education Positions Project, Project PSEP (Hammond, 1995), Project EPIC, Educating Personnel in our Communities (Hammond, 2000) and Project PARA, Supporting Paraprofessionals for Special Education Positions (Hammond , 2006) are a variety of projects implemented in a combination of urban and rural communities. Individuals selected for these projects were primarily paraprofessionals in special education classrooms who were interested in becoming certified in special education. These individuals were not able to afford university training and were resistant to relocate to another community to seek possible funding support through scholarships or grant funds. In addition, they were members of a place bound community primarily due to cultural background and beliefs. The Project Director determined paraprofessionals would be the most ideal group of professionals to support for training and certification in special education as they knew the demands of a special education teacher and they were very likely to remain in the community after they had obtained their degree. Since these individuals had experienced years in a special education setting, they knew what would be expected of them as a teacher and would not experience the typical "burn-out" that other individuals experienced who had not been a paraprofessional in a classroom. Supporting this selected group would address increasing special education teacher shortages and retention of these teachers.

When these projects were offered to community members, there was an abundant number of responses. Selected individuals received funding to pay for their tuition, fees and textbooks. They also were provided tutors, when needed, and mentor colleagues as support. Each participant was monitored closely to provide the professional advising for coursework and the professional support to complete coursework in a timely fashion. Individuals from these projects formed professional cohorts which greatly assisted in maintaining their satisfaction in their training programs. Individuals were also given a choice of taking the coursework from the area university or a community college in their home and work community for courses at the freshman and sophomore levels. The comprehensive support provided by the projects was invaluable to these individuals in assisting them to complete their degrees and become certified in the special education field. In contrast to this support system is the one many undergraduate students encounter. It is all too common that undergraduate students seeking a similar degree in a university setting experience confusion and frustration from receiving ineffective advising from university faculty. All too often students relate a feeling of being lost in a very complicated university system. With the support of these projects, the participants' confusions and frustrations were greatly reduced.

Project LISTOS, Language Interface and Support To Our Students, (Ingalls, 1996) and Project AIMED, American Indian Master's of Education Project (Ingalls, 2002) are two examples of projects that used distance learning strategies to meet the shortage of educators properly trained to teach American Indian students. Participants selected for these projects were teachers certified in general or special education, however, were not trained in providing quality bilingual special education services. All participants selected for these projects acknowledged a great need to further their training, however, were place bound to their communities and did not choose to travel to another community for training. Both projects provided graduate level coursework in bilingual special education to individuals who taught at Reservation Schools.

An additional issue addressed by Project LISTOS and Project AIMED was the need to train teachers who were culturally and linguistically similar to the student population. Since these Projects focused on training teachers to effectively work with American Indian students and their families, a priority goal of the Projects was to recruit teachers who were also from American Indian backgrounds. With the proper training, these participants were ideal candidates to provide cultural compatibility and culturally responsive teaching. Sileo and Prater (2000) discussed the importance of striving to have a cultural representation among the teaching staff for students from culturally diverse backgrounds. This representation provides a commonality of cultural backgrounds between the school and the home, enhances communication with family members, and promotes improved instruction within the classroom.

Project LISTOS and Project AIMED instilled a great deal of pride in the participants as they not only accomplished coursework, but realized their accomplishments were making a difference in the children and families they served at their schools. Their increased skill levels assisted them in making quality changes in their instruction, 
educational materials, and interactions with community members. These projects provided all participants with paid tuition, fees and a book allowance. Along with this financial support, the Project Director utilized strategies of providing distance learning, developing professional cohorts, providing mentors to support project activities, and allocating travel funds to support a variety of educational opportunities. Satisfaction among the participants was very high and their professional accomplishments were commensurate with their satisfaction.

\section{RESULTS}

Preparing Individuals for Special Education Positions Project, Project EPIC and Project PARA graduated 80 individuals with a Bachelors Degree in special education. Since Project PARA is still in operation, it is anticipated this project will help to certify an additional 30 individuals in special education. These newly graduated special education teachers all obtained teaching positions in their community schools and served children with disabilities. Additionally, these teachers have remained in their communities alleviating the critical shortage of special education teachers in these place bound communities.

Project LISTOS and AIMED graduated 92 students with a Masters Degree in Bilingual Special Education. These master teachers had specific training relating to the cultural and linguistic attributes of the American Indian group where they worked. The specific training these individuals received has helped to reduce the number of inappropriate referrals to special education. Additionally, the training has improved the instruction students with disabilities receive as the curriculum is more culturally sensitive to the learning styles of the students that they teach. These graduates have positively impacted five American Indian communities. Of the 92 graduates all but three have been retained in the communities where they previously worked. Of the three that did not remain in the community, two have left to teach in schools that serve a high percentage of American Indian children. As a result of these projects, highly qualified special educators have helped to alleviate the critical shortage that plagued these rural communities.

\section{CONCLUSIONS AND FUTURE DIRECTIONS}

Personnel preparation projects are designed to reduce the shortage of teachers in a variety of specific areas in the education fields. In order to better reduce the shortage of critical personnel in the education field, these projects should not only focus on graduating highly qualified personnel, but also on assuring that these graduates will remain in the field and are retainable in the communities where the critical shortage was identified. If the graduates do not meet these two criteria, the project is not successful in reducing the shortage in the identified communities. Therefore, future personnel preparation projects need to identify communities where a critical shortage of the targeted personnel exists. The projects should also try to identify those factors that would most likely keep trained teachers in these communities once they have received their specific degrees. Identification of likely retention factors would then dominate the recruitment efforts and guidelines for these projects. Following this type of format would better serve the federal government's attempts to alleviate the critical shortages in the communities of the projects that are funded.

\section{AUTHOR INFORMATION}

Dr. Lawrence Ingalls is an Associate Professor at the University of Texas @ El Paso in the Department of Educational Psychology and Special Services. He has many years of teaching experience working with students with mild to severe disabilities. A major area of interest for him has been on developing educational programs and assessment methodologies of students from culturally and linguistically diverse populations. Of particular interest is research involving American Indian children and their families. Dr. Ingalls has successfully been federally funded to implement a variety of personnel preparation grants throughout the years.

Dr. Helen Hammond is an Associate Professor at the University of Texas @ El Paso in the Department of Educational Psychology and Special Services. Her professional classroom experiences have primarily involved working in early childhood special education and with students with severe disabilities. Her major research interests have focused on family involvement in special education and early intervention. Over the past fifteen years, Dr. Hammond has been actively involved directing a variety of personnel preparation projects for special education teachers. 


\section{REFERENCES}

1. Goldman, R. L. (2004). Project LEAD: A training program for minority educators in special education and educational leadership. College Student Journal, 38(2), 285 - 292.

2. Hammond, H. (1995). Federally funded grant: Preparing personnel for special education positions (Project PSEP). Office of Special Education Programs, Washington. D.C.

3. Hammond, H. (2000). Federally funded grant: Educating paraprofessionals in our communities (Project EPIC). Office of Special Education Programs. Washington, D. C.

4. Hammond H. (2006). Federally funded grant: Supporting paraprofessionals for special education positions, (Project PARA). Office of Special Education Programs. Washington, D. C.

5. Ingalls, L. (1996). Federally funded grant: Language interface and support to our students (Project LISTOS). Office of Special Education Programs. Washington, D.C.

6. Ingalls, L. (20020. Federally funded grant: American Indian masters of education degree (Project AIMED). Office of Special Education Programs. Washington, D. C.

7. Lang, M. \& Fox, L. (2003). Breaking with tradition: Providing effective professional development for instructional personnel supporting students with severe disabilities. Teacher Education an Special Education, 26(1), 17-26.

8. Ludlow, B. L., Conner, D., \& Schechter, J. (2005). Low incidence disabilities and personnel preparation for rural areas: Current status and future trends. Rural Special Education Quarterly: Low incidence disabilities. Available: http://findarticles.com/p/articles/mi qa4052/is_200507/ai_n15643599.

9. Scheuermann, B., Webber, J., Boutot, A., \& Goodwin, m. (2003). Problems with personnel preparation in autism spectrum disorders. Focus on Autism and Other Developmental Disorders, 18(3), 197-206.

10. Sileo, T.W. \& Prater, M.A. (2000). Teacher education: Reforms and restructuring. In M.A. Winzer \& K. Mazurek (Eds). Special education in the $21^{\text {st }}$ century: Issues of inclusion and reform (pp. $106-134$ ). Washington, DC: Gallaudet University Press.

11. Westling, D. \& Fox, E. (2004). Philosophy and best practices for educating persons with severe disabilities. In D. E. Westling \& E. Fox, Teaching students with severe disabilities ( $3^{\text {rd }}$ ed. pp. 30 - 58). Englewood Cliffs, NJ: Prentice Hall.

12. Williams, J. M., Martin, S. M., \& Hess, R. K. (2002). Personnel preparation and service delivery issues in rural areas. Rural Special Education Quarterly: Personnel preparation and service. Available: http://findarticles.com/p/articles/mi_qa4052/is_200210/ai_n9135906/. 
NOTES 